\title{
INVESTIGATION OF THE INFLUENCE OF AN INTERMEDIATE HINGE SUPPORT IN THE PROBLEM OF BENDING OF AN ELASTICALLY RESTRAINED ORTHOTROPIC BEAM
}

\author{
S. P. STEPANYAN *
}

Chair of Numerical Analysis and Mathematical Modeling, YSU, Armenia

In this paper, based on the refined theory of orthotropic plates of variable thickness, a system of differential equations is obtained for solving the problem of bending of an elastically restrained beam with an intermediate condition. The beam thickness is constant and is subject to a uniformly distributed load. The effects of transverse shear are also taken into account. Passing to dimensionless quantities, an analytical closed solution is obtained. The question of the influence of changing the place of application of the intermediate condition on the solution is discussed. Depending on the location of the hinge bearing, the question of optimality was posed and resolved according to the principle of minimum maximum deflection. The results are presented in both tabular and graphical form. Based on the results obtained, appropriate conclusions are drawn.

https://doi.org/10.46991/PYSU:A/2021.55.1.064

MSC2010: 74K10.

Keywords: elastically fastened support, bending, transverse shear, minimax, optimality.

Introduction. It is known that the structural elements used in different building structures are in the form of beams, plates or shells. To find out and ensure the bearing capacity of such thin-walled elements, sometimes it becomes necessary to solve the bending problem with an additional intermediate condition. Considering that modern structural elements are mainly anisotropic, the study of the stress-strain state must be carried out according to refined theories. In the present work, the problem under consideration is solved precisely according to this theory. This paper addresses the following issues:

1. Obtaining and solving a differential equation describing the bending of an orthotropic beam with the corresponding boundary conditions.

2. Numerical calculations for different values of the parameter of the elastically restrained support and with variation of the place of application of the hinged support, taking into account the transverse shear and without it.

\footnotetext{
* E-mail: seyran.stepanyan@ysu.am
} 
3. Based on the principle of minimum maximum deflection, determining the best option for the place of application of the hinge bearing.

Problem Setting. Consider an orthotropic beam of length $l$, constant width $b$, and constant thickness $h$. The main directions of the anisotropy of the material are parallel to the coordinate axes $x, y, z$. The beam is elastically clamped at the right end, the left edge is rigidly fastened, and at some distance from the left edge it is hingedly supported. The beam is under a uniformly distributed load (Fig. 1). The conditions of the considered elastically fastened support during transverse bending of the beam are known [1], and have the form:

$$
\frac{d w}{d x}=D\left(a N_{x}-M_{x}\right), \quad w=a \frac{d w}{d x}+B N_{x},
$$

here $w$ is the deflection; $N_{x}$ and $M_{x}$ are the transverse force and bending moment of the beam; $D$ and $B$ are the parameters of the elastically restrained support, which are related by the relation

$$
D=\frac{3 B}{a^{2}}
$$

and are the reciprocal of the stiffness of the support for rotation and vertical displacement, respectively.

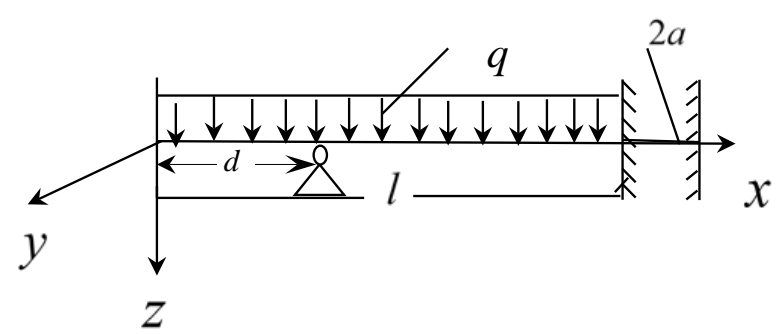

Fig. 1. The Beam center axis and load shape.

By using the refined theory of orthotropic plates of variable thickness [1], we obtain the differential equations for the problem of bending of the considered beam:

$$
\left\{\begin{array}{l}
\left(E h^{2} \frac{d^{2} h}{d x^{2}}\right) \frac{d^{2} w}{d x^{2}}-h\left(8+\chi h \frac{d^{2} h}{d x^{2}}\right) \frac{d \varphi_{1}}{d x}-16 \frac{d h}{d x} \varphi_{1}=12 q, \\
E h^{2} \frac{d^{3} w}{d x^{3}}+2 E h \frac{d h}{d x} \cdot \frac{d^{2} w}{d x^{2}}-\chi h^{2} \frac{d^{2} \varphi_{1}}{d x^{2}}-2 \chi h \frac{d h}{d x} \cdot \frac{d \varphi_{1}}{d x}+\varphi_{1}=0,
\end{array}\right.
$$

here $E$ is Young's modulus; $\chi$ - takes into account the effect of the transverse shear of the deformation $e_{x z} ; \varphi_{1}$ is function characterizing the distribution of the shear stress $\tau_{x z}$ on the median plane $z=0$ of the beam.

The boundary conditions for hinged support are as follows:

$$
w=0, \quad M_{x}=0,
$$

and for $x=l$ in the form (1). 
Consider a beam of the constant thickness $h$. We will apply the following substitution with the variables:

$$
\begin{gathered}
x=l \bar{x}, h=m_{1} l, b=m_{2} l, d=m_{4} l, a=m_{3} l, \varphi_{1}=E \bar{\varphi}, w=h \bar{w}, E a_{55}=\chi, \\
q=E \bar{q} m_{1}^{3}, \quad D=\frac{3 \bar{B}}{E m_{3}^{2} l^{l}}, \quad B E l=\bar{B}, N_{x}=E h^{2} \bar{N}_{x}, M_{x}=E h^{3} \bar{M}_{x} .
\end{gathered}
$$

From the system (3) we get:

$$
\left\{\begin{array}{l}
\frac{d \varphi}{d \bar{x}}=-\frac{3}{2} m_{1}^{2} \bar{q} \\
\frac{m_{1}^{3} d^{3} \bar{w}}{d \bar{x}^{3}}+8 \bar{\varphi}=0 .
\end{array}\right.
$$

The boundary conditions, taking into account (5), will be: at $\bar{x}=0$

$$
\left.\bar{w}\right|_{\bar{x}=0}=0,\left.\quad \frac{d \bar{w}}{d \bar{x}}\right|_{\bar{x}=0}=0 ;
$$

at $\bar{x}=m_{4}$

$$
\left.\bar{w}\right|_{\bar{x}=m_{4}}=0,\left.\quad \bar{M}\right|_{\bar{x}=m_{4}}=0 ;
$$

at $\bar{x}=1$

$$
\begin{gathered}
\left.\bar{w}\right|_{\bar{x}=1}=\left.m_{3} \frac{d \bar{w}}{d \bar{x}}\right|_{\bar{x}=1}+\left.\bar{B} m_{1} \bar{N}\right|_{\bar{x}=1} \\
\left.\frac{d \bar{w}}{d \bar{x}}\right|_{\bar{x}=1}=\left.\frac{3 \bar{B}}{m_{3}^{2}}\left(m_{1} m_{3} \bar{N}_{\bar{x}}-m_{1}^{2} \bar{M}_{\bar{x}}\right)\right|_{\bar{x}=1} .
\end{gathered}
$$

Having solved the system (6), we obtain:

$$
\begin{gathered}
\bar{\varphi}=-\frac{3}{2} m_{1}^{2} \bar{q} \cdot \bar{x}+c_{1}, \\
\bar{w}=\frac{\bar{q}}{2 m_{1}} \bar{x}^{4}-\frac{4}{3 m_{1}^{3}} c_{1} \bar{x}^{3}+\frac{1}{2} c_{2} \bar{x}^{2}+c_{3} \bar{x}+c_{4} .
\end{gathered}
$$

For $\bar{N}_{x}$ and $\bar{M}_{x}$ we will have

$$
\begin{gathered}
\bar{N}_{x}=m_{1} m_{2} \bar{q} \bar{x}+\frac{2 m_{2}}{3 m_{1}} c_{1}, \\
\bar{M}_{x}=-\frac{1}{2} m_{2} \bar{q} \bar{x}^{2}+\frac{2}{3} \cdot \frac{m_{2}}{m_{1}} c_{1} \bar{x}-\frac{1}{12} m_{1} m_{2} c_{2}-\frac{1}{4} m_{1}^{2} m_{2} \chi \bar{q} .
\end{gathered}
$$

Inserting (11), (12) and (13) into (9), we obtain a system of linear equations for the unknown coefficients $c_{1}, c_{2}, c_{3}$ and $c_{4}$.

The system looks like:

$$
\left\{\begin{array}{l}
A_{11} c_{1}+A_{12} c_{2}+A_{13} c_{3}+A_{14} c_{4}=B_{1} \\
A_{21} c_{1}+A_{22} c_{2}+A_{23} c_{3}+A_{24} c_{4}=B_{2} \\
A_{31} c_{1}+A_{32} c_{2}+A_{33} c_{3}+A_{34} c_{4}=B_{3} \\
A_{41} c_{1}+A_{42} c_{2}+A_{43} c_{3}+A_{44} c_{4}=B_{4}
\end{array}\right.
$$


where

$$
\begin{gathered}
A_{11}=\frac{4 m_{3}}{m_{1}^{3}}-\frac{2 m_{2} \bar{B}}{3}-\frac{4}{3 m_{1}^{3}}, \quad A_{12}=\frac{1}{2}-m_{3}, \quad A_{13}=1-m_{3}, \\
A_{14}=1, \quad A_{21}=\frac{2 \bar{B} m_{2}}{m_{3}^{2}}-\frac{2 m_{2} \bar{B}}{m_{3}}-\frac{4}{m_{1}^{3}} ; \\
A_{22}=1-\frac{1}{4} \cdot \frac{m_{1}^{3} m_{2} \bar{B}}{m_{3}^{2}}, \quad A_{23}=1, \quad A_{24}=0, \quad A_{31}=\frac{4 m_{4}^{3}}{3 m_{1}^{3}}, \\
A_{32}=-\frac{1}{2} m_{4}^{2}, \quad A_{33}=-m_{4}, \quad A_{34}=-1 ; \\
A_{41}=\frac{2 m_{2} m_{4}}{3 m_{1}^{2}}, \quad A_{42}=-\frac{m_{1} m_{2}}{12}, \quad A_{43}=0, \quad A_{44}=0, \\
B_{2}=\frac{3 \bar{B} m_{1}^{4} m_{2} \chi \bar{q}}{8 m_{3}^{2}}-\frac{3 \bar{B} m_{1}^{2} m_{2} \bar{q}}{m_{3}}+\frac{3 \bar{B} m_{1}^{2} m_{2} \bar{q}}{2 m_{3}^{2}}-\frac{2 \bar{q}}{m_{1}}, \quad m_{1}, \quad \bar{B} m_{1}^{2} m_{2} \bar{q}-\frac{\bar{q}}{2 m_{1}} ; \\
B_{4}=\frac{1}{8} m_{1}^{2} m_{2} \chi \bar{q}+\frac{1}{2} m_{2} m_{4}^{2} \bar{q} .
\end{gathered}
$$

\begin{tabular}{|c|c|c|c|c|c|c|c|}
\hline \multirow{2}{*}{\multicolumn{2}{|c|}{$\chi=0$}} & \multicolumn{2}{|c|}{$\begin{array}{l}\bar{B}=0 ; \bar{x}=0 \\
\bar{B}=1 ; \bar{x}=1\end{array}$} & \multicolumn{2}{|c|}{$\begin{array}{l}\bar{B}=0 ; \bar{x}=0 \\
\bar{B}=5 ; \bar{x}=1\end{array}$} & \multicolumn{2}{|c|}{$\begin{array}{c}\bar{B}=0 ; \bar{x}=0 \\
\bar{B}=10 ; \bar{x}=1\end{array}$} \\
\hline & & $\bar{x} \in\left[0 ; m_{4}\right]$ & $\bar{x} \in\left[m_{4} ; 1\right]$ & $\bar{x} \in\left[0 ; m_{4}\right]$ & $\bar{x} \in\left[m_{4} ; 1\right]$ & $\bar{x} \in\left[0 ; m_{4}\right]$ & $\bar{x} \in\left[m_{4} ; 1\right]$ \\
\hline \multirow{2}{*}{$m_{4}=0.1$} & $\bar{w}_{\max }$ & 0.000065 & 0421428 & 0.000065 & 0.399637 & 0.000065 & 0.367343 \\
\hline & $\bar{x}_{\max }$ & 0.05784 & 0.47844 & 0.05784 & 0.47419 & 0.05785 & 0.46744 \\
\hline \multirow{2}{*}{$m_{4}=0.2$} & $\bar{w}_{\max }$ & 0.001039 & 0263133 & 0.001039 & 0.24968 & 0.001039 & 0.22962 \\
\hline & $\bar{x}_{\max }$ & 0.11569 & 0.53637 & 0.11569 & 0.53256 & 0.11569 & 0.52657 \\
\hline \multirow{2}{*}{$m_{4}=0.3$} & $\bar{w}_{\max }$ & 0.005264 & 0.154268 & 0.005264 & 0.146529 & 0.005264 & 0.135053 \\
\hline & $\bar{x}_{\max }$ & 0.17354 & 0.59427 & 0.17354 & 0.59077 & 0.17354 & 0.58545 \\
\hline \multirow{2}{*}{$m_{4}=0.4$} & $\bar{w}_{\max }$ & 0.016638 & 0.083251 & 0.016638 & 0.079084 & 0.016638 & 0.073116 \\
\hline & $\bar{x}_{\max }$ & 0.23139 & 0.65208 & 0.23139 & 0.64854 & 0.23138 & 0.64349 \\
\hline \multirow{2}{*}{$m_{4}=0.5$} & $\bar{w}_{\max }$ & 0.040621 & 0.040062 & 0.040621 & 0.037802 & 0.04062 & 0.03487 \\
\hline & $\bar{x}_{\max }$ & 0.28923 & 0.70965 & 0.28923 & 0.70514 & 0.28923 & 0.69931 \\
\hline \multirow{2}{*}{$m_{4}=0.6$} & $\bar{w}_{\max }$ & 0.084231 & 0.016260 & 0.084231 & 0.014725 & 0.084231 & 0.013031 \\
\hline & $\bar{x}_{\max }$ & 0.34708 & 0.76663 & 0.34708 & 0.75886 & 0.34708 & 0.74955 \\
\hline \multirow{2}{*}{$m_{4}=0.7$} & $\bar{w}_{\max }$ & 0.156049 & 0.004888 & 0.156049 & 0.003546 & 0.156049 & 0.002231 \\
\hline & $\bar{x}_{\max }$ & 0.404925 & 0.82183 & 0.404925 & 0.80446 & 0.40492 & 0.78458 \\
\hline \multirow{2}{*}{$m_{4}=0.8$} & $\bar{w}_{\max }$ & 0.266213 & 0.000684 & 0.266213 & 0.005 & 0.266213 & 0.003 \\
\hline & $\bar{x}_{\max }$ & 0.46277 & 0.87007 & 0.46277 & 0.850 & 0.46277 & 0.82 \\
\hline \multirow{2}{*}{$m_{4}=0.9$} & $\bar{w}_{\max }$ & 0.426422 & 0.0 & 0.426422 & 0.0 & 0.436422 & 0.0 \\
\hline & $\bar{x}_{\max }$ & 0.52062 & 0.90002 & 0.52062 & 0.900002 & 0.52062 & 0.90 \\
\hline
\end{tabular}

Table 1

Maximum deflection values and extremum point depending on the parameter $m_{4}$ and $\bar{B}$ at $\chi=0$.

The found value and inserting it into (10)-(13), we obtain expressions for the basic quantities.

Computational Part. Consider a numerical example. Let

$$
m_{1}=0.1, m_{2}=0.3, m_{3}=0.1 ; \chi=0,5 \text { and } 10 ; \bar{B}=0,5 \text { and } 10 ;
$$


$m_{4}=0.1,0.2,0.3,0.4,0.5,0.6,0.7,0.8$ and $0.9 ; \quad \chi=0,5$ and 10.

For these values of the parameters, solving the system (14), we obtain the values for $c_{1}, c_{2}, c_{3}$ and $c_{4}$.

By inserting found value into expressions (11), (12) and (13), we obtain the required basic functions. The calculation results are shown in Figs. 2, 3 and Tabs. 1, 2.

Maximum deflection values and extremum point depending on the parameter $m_{4}$ and $\bar{B}$ at $\chi=5$

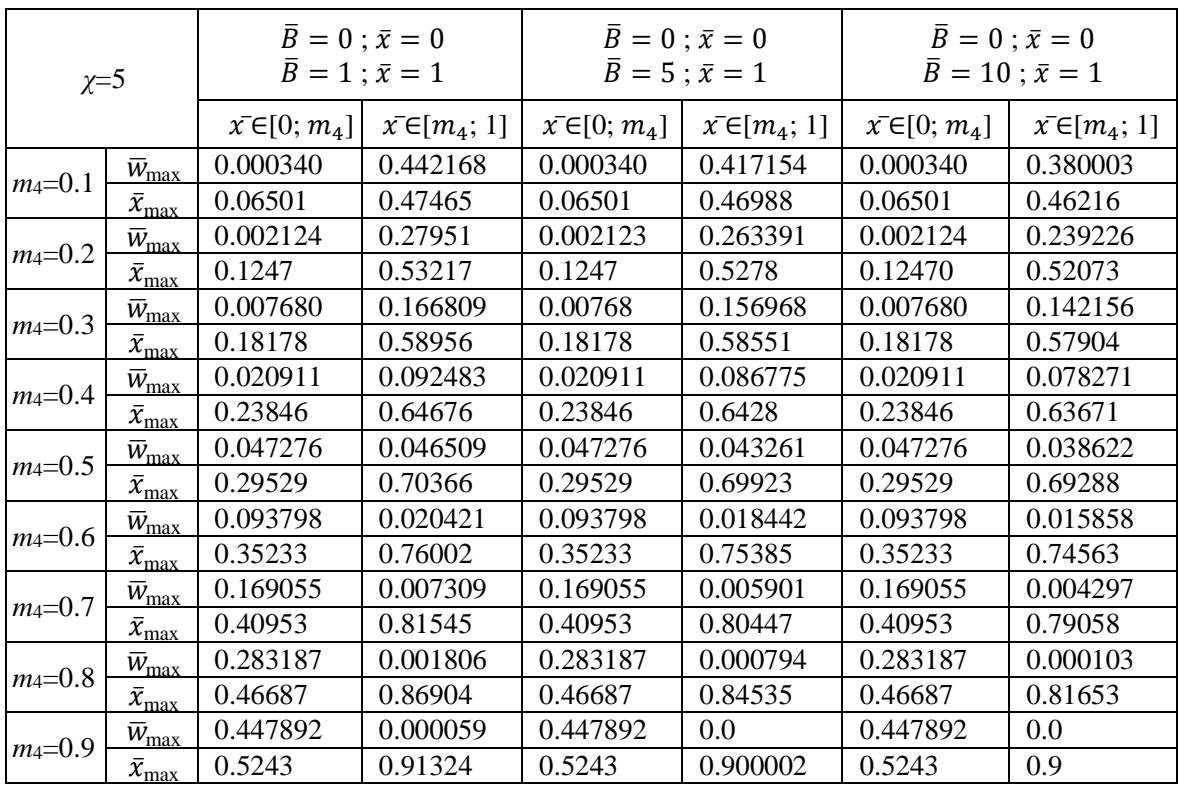

Tabs. 1 and 2 show, respectively, the values of the maximum and the place of its acceptance on the segments $\left[0 ; m_{4}\right]$ and $\left[m_{4} ; 1\right]$ at $\chi=0, \chi=5$ and at different values of some the basic parameters.

Now, answering the third question, we see (see Figs. 2, 3 and Tabs. 1 and 2) that the maximum value of the deflection $\bar{x} \in\left[0 ; m_{4}\right]$ and $\bar{x} \in\left[m_{4} ; 1\right]$ simultaneously on two parts of the beam will be minimal at $m_{4}=0.5$.

In the scientific literature, you can find many works devoted to the description and application of different methods for studying the bending of Thin-Waled elements with different boundary conditions, including under the condition of an elastically restrained support [1-20]

\section{Conclusion.}

1. The data given in Tabs. 1 and 2 show that in all cases the maximum deflection value at the intervals $\bar{x} \in\left[0 ; m_{4}\right]$ and $\bar{x} \in\left[m_{4} ; 1\right]$ will not be in the middle of these segments, but at the closer to the hinge support.

2. Taking into account the effect of transverse shear deformations (cases $\chi>0$ ), as expected, with the same values of other quantities, leads to an increase in deflections.

3 . In the case of an elastically restrained support (cases $\bar{B}>0$ ), and with the same values of other values, it leads to an increase in deflections, compared to rigid restraint (cases $\bar{B}=0$ ). 
4. Changing parameter $\bar{B}$ does not affect the amount of deflection in the interval $\bar{x} \in\left[0 ; m_{4}\right]$.
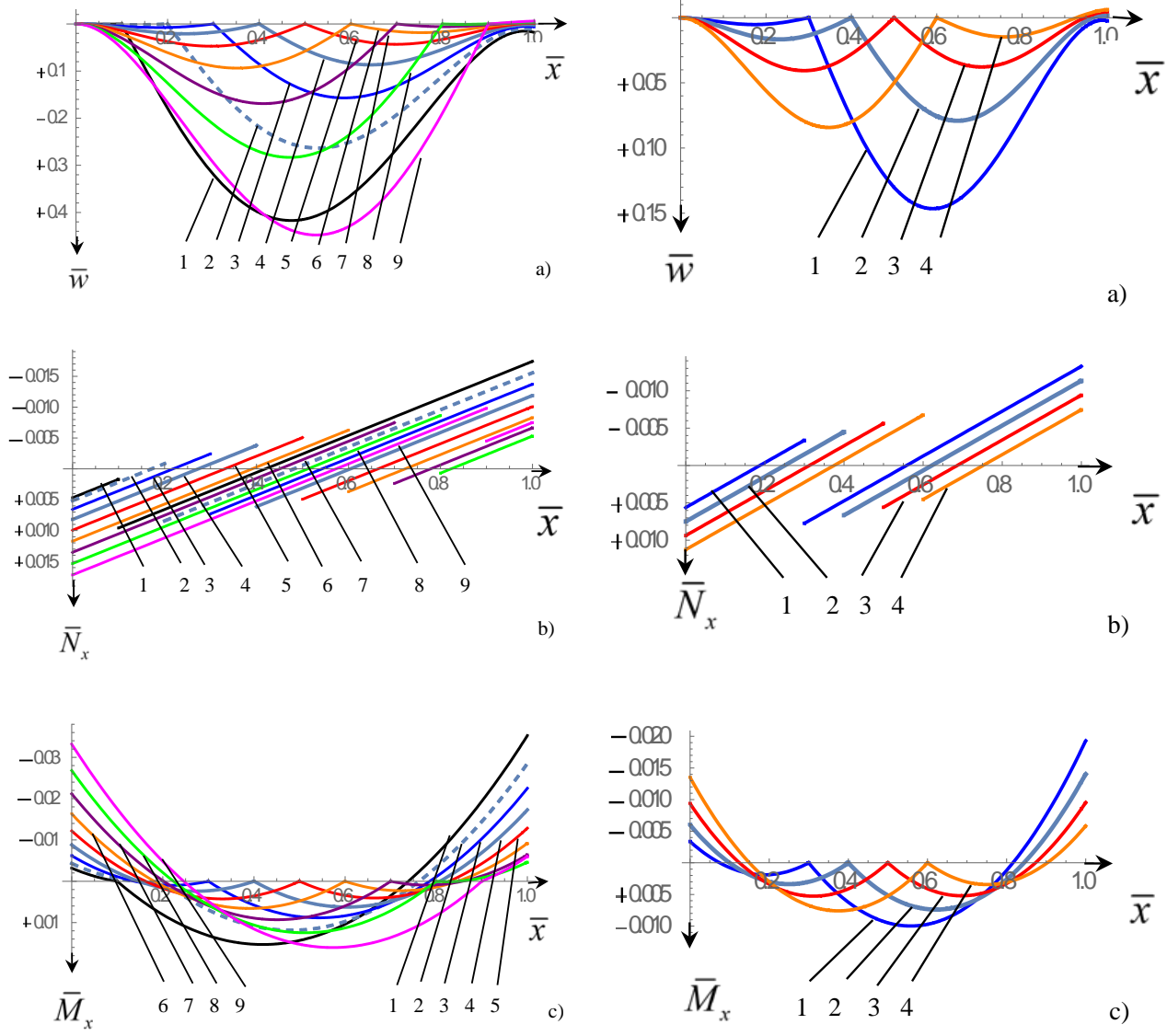

Fig. 2. Distribution of deflection (a), transverse force (b), and bending moment (c) depending on the parameter $m_{4}$ at $\bar{B}=5, \chi=5$.

$1 \rightarrow m_{4}=0.1 ; 2 \rightarrow m_{4}=0.2$;

$3 \rightarrow m_{4}=0.3 ; 4 \rightarrow m_{4}=0.4$

$5 \rightarrow m_{4}=0.5 ; 6 \rightarrow m_{4}=0.6$

$7 \rightarrow m_{4}=0.7 ; 8 \rightarrow m_{4}=0.8 ; 9 \rightarrow m_{4}=0.9$.

Fig. 3. Distribution of deflection (a), transverse force $(b)$, and bending moment (c) depending on the parameter $m_{4}$ at $\bar{B}=5, \chi=0$. $1 \rightarrow m_{4}=0.3 ; 2 \rightarrow m_{4}=0.4$; $3 \rightarrow m_{4}=0.5 ; 4 \rightarrow m_{4}=0.6$.

Received 15.01.2021

Reviewed 09.02.2021

Accepted 23.02.2021

\section{R E F E R E N C E S}

1. Kirakosyan R.M., Stepanyan S.P. Non-Classical Problem of Bending of an Orthotropic Beam of Variable Thickness with Elastically Clamped Support. NAS RA Reports 114 : 3 (2014), 205-212 (in Russian). 
2. Kirakosyan R.M. Applied Theory of Orthotropic Plates of Variable Thickness, which Takes into Account the Effect of Transverse Shear Deformation. Yer., Gitutyun (2000), 122 p. (in Russian).

3. Kirakosyan R.M. On One Non-Clasical Problem of a Bend of an Elastically Fastened Round Plate. NAS RA Reports 115 : 4 (2015), 284-289 (in Russian).

4. Kirakosyan R.M., Stepanyan S.P. The Non-Classical Boundary Value Problem of Partially Loaded Round Orthotropic Plate, Elastically Pinch Along the Edge. Izv. NAS of Armenia. Mechanics 69 : 3 (2016), 59-70 (in Russian).

5. Kirakosyan R.M., Stepanyan S.P. Stability of the Rod with Allowance for the Reduction of the Compressive Force by an Elastically Clamped Support. Izv. NAS of Armenia Mechanics 70 : 3 (2017), 57-66 (in Russian).

6. Kirakosyan R.M., Stepanyan S.P. Non-Classical Problem of Bend of an Orthotropic Annular Plate of Variable Thickness with an Elastically Clamped Support. Proc. YSU A: Phys. Math. Sci. 51 (2017), 168-176.

http://doi.org/10.46991/PYSU:A/2017.51.2.168

7. Kirakosyan R.M., Stepanyan S.P. The Non-Classical Problem of an elastically clamped orthotropic beam of compressive forces and transverse load. Proceedings of the YSU. Physical and Mathematical Sciences 52 : 2 (2018), 101-108.

http://doi.org/10.46991/PYSU:A/2018.52.2.101

8. Batista M. Stability of clamped-elastically supported elastic beam subject to axial compression. International Journal of Mechanical Sciences 155 (2019), 1-8.

https://doi.org/10.1016/j.ijmecsci.2019.02.030

9. Papargyri-Beskou S., Tsepoura K.G, Polyzos D., Beskos D.E. Bending and stability analysis of gradient elastic beams. International Journal of Solids and Structures 2 : 40 (2003), 385-400.

10. Laszek S., Kwiaton P. Mathematical Modeling of Mechanical Phenomena in the Gantry Crane Beam. Journal of Applied Mathematics and Computational Mechanics 3 : 16 (2017), 97-104.

11. Lazarev N.P., Rudoy E.M. Optimal Size of a Rigid Thin Stiffener Reinforcing an Elastic Plate on the Outer Edge. Journal of Applied Mathematics and Mechanics 9 : 97 (2017), $1120-1127$.

https://doi.org/10.1002/zamm. 201600291

12. Song Zh., Cao Q., Dai Q. Free Vibration of Truncated Conical Shells with Elastic Boundary Constraints and Added Mass. International Journal of Mechanical Sciences 155 (2019), 286-294. https://doi.org/10.1016/j.ijmecsci.2019.02.039

13. Berchio E., Buoso D., Gazzolla F., Zucco D. A Minimaxmax Problem for Improving the Torsional Stability of Rectangular plates. Journal of Optimization Theory and Applications 177 : 1 (2018), 64-92. (2018). https://doi.org/10.1007/s10957-018-1261-1

14. Ishaquddin Md., Gopalakrishnan S. A Novel Weak Form Quadrature Element for Gradient Elastic Beam Theories. Applied Mathematical Modelling 77 : 1 (2019), 1-16.

15. Grygorowicz M., Magnucka-Blandzi E. Mathematical Modeling for Dynamic Stability of Sandwich Beam with Variable Mechanical Properties of Core. Applied Mathematics and Mechanics 10 : 37 (2016), 1361-1374.

16. Abubakr E.S.M. Galerkin Method for Bending Analysis of Beams on Non-homogeneous Foundation. J. of Applied Mathem. and Computational Mechanics 3 : 16 (2017), 61-72.

17. Su Z., Wang L., Sun K. et al. Transverse Shear and Normal Deformation Effects on Vibration Behaviors of Functionally Graded Micro-beams. Appl. Math. Mech.-Eng. Ed. 41 : 9 (2020), 1303-1320. http://doi.org/10.1007/s10483-020-2662-6

18. Jin Ya., Wang W., Djafari-Rouhani B. Asymmetric Topological State in an Elastic Beam Based on Symmetry Principle. International Journal of Mechanical Sciences 186 (2020). http://doi.org/10.1016/j.ijmecsci.2020.105897 
19. Fernandes R.J., Sunkad A. A Study on Probability Failure of RC Beam in Single Bay Portal Frame for Varying Live Load. IOSR Journal of Mechanical and Civil Engineering (IOSR-JMCE) $17: 5$ (2020), 16-20. http://doi.10.9790/1684-1705041620

20. Adah E.I., Ibearugbulem O.M., Ubi S.E, Idagu F.O. Analysis of a Two-Way Continuous Plate Based on Beam Analogy. IOSR J. Mech. Civil Eng., Ser. I 18 : 1 (2021), 59-67. http://doi.10.9790/1684-1801015967

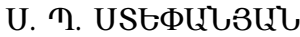

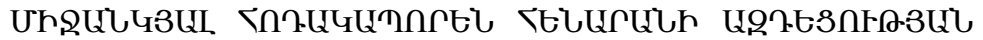

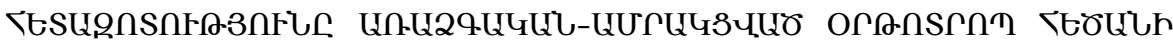

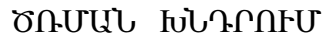

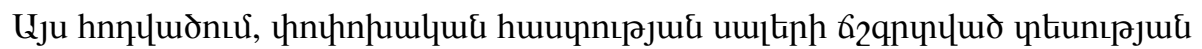

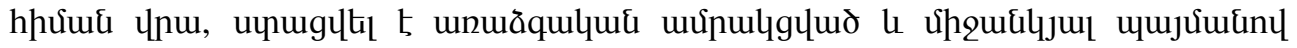

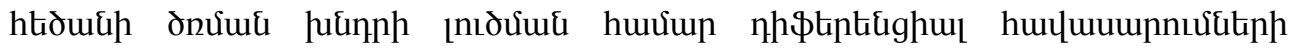

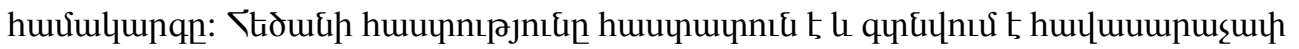

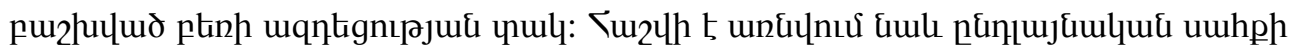

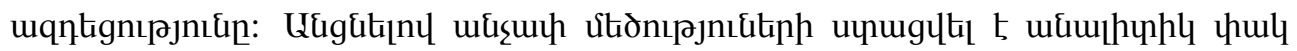

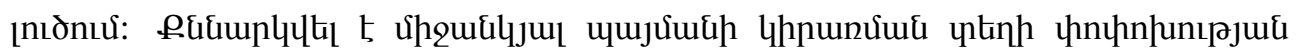

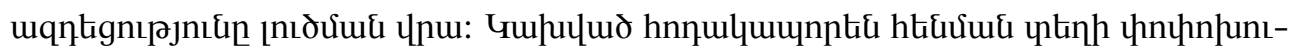

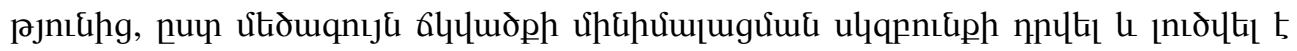

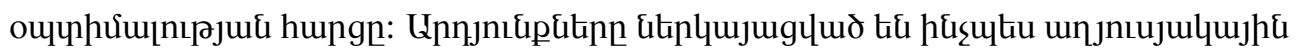

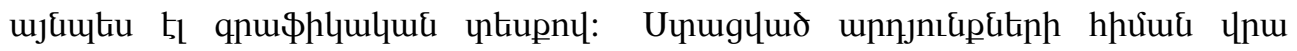

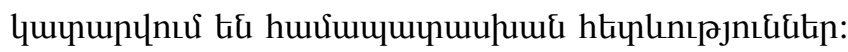

\section{С. П. СТЕПАНЯН}

\section{ИССЛЕДОВАНИЕ ВЛИЯНИЯ ПРОМЕЖУТОЧНОЙ ШАРНИРНОЙ ОПОРЫ В ЗАДАЧЕ ИЗГИБА УПРУГО-ЗАЩЕМЛЕННОЙ ОРТОТРОПНОЙ БАЛКИ}

В этой статье на основе уточненной теории ортотропных пластин переменной толщины получена система дифференциальных уравнений для решения задачи изгиба упруго-защемленной балки с промежуточным условием. Толщина балки постоянная и находится под действием равномерно распределенной нагрузки. Учитываются также влияния поперечного сдвига. С перехом к безразмерным величинам получено аналитическое замкнутое решение. Обсуждается вопрос влияния изменения места приложения промежуточного условия на решение. В зависимости от места нахождения шарнирного опирания поставлен и решен вопрос оптимальности по принципу минимальности максимального прогиба. Результаты представлены как в табличной, так и в графической форме. На основе полученных результатов делаются соответствующие выводы. 